
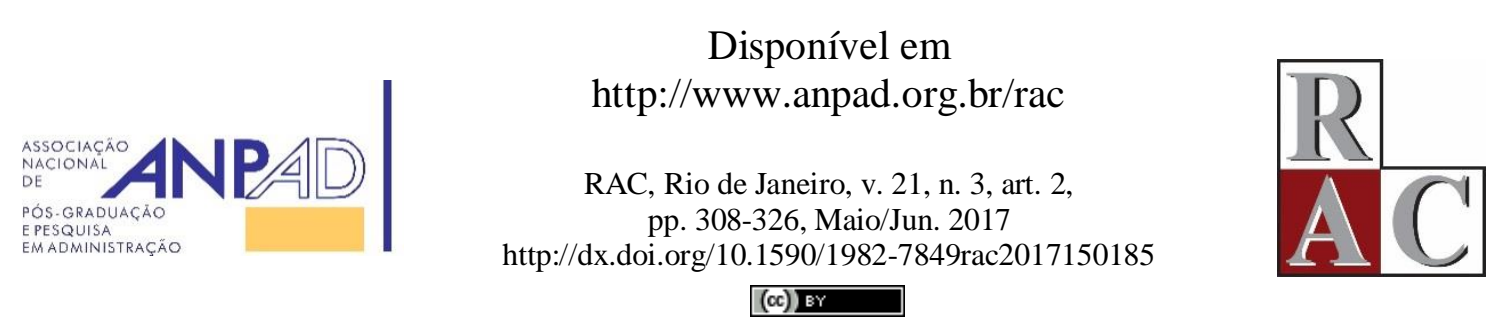

\title{
A Teoria Queer e os Estudos Organizacionais: Revisando Conceitos sobre Identidade
}

\author{
Queer Theory and Organizational Studies: Reviewing Identity Concepts
}

Eloisio Moulin de Souza ${ }^{1}$

Universidade Federal do Espírito Santo ${ }^{1}$

Artigo recebido em 10.07.2015. Última versão recebida em 20.10.2015. Aprovado em 10.11.2015. Publicado online em 22.08.2016 


\title{
Resumo
}

A teoria queer desenvolveu-se incialmente na década de noventa, nas ciências sociais e humanas, principalmente nos estudos literários e linguísticos, sendo posteriormente incorporada aos estudos organizacionais. Entretanto, apesar de sua aplicação aos estudos organizacionais, ainda existe uma lacuna acerca do debate sobre seus conceitos e significados. Por isso, este artigo objetiva aprofundar e revisar o debate sobre os aspectos desenvolvidos por essa teoria, focando-se nos conceitos relacionados à produção identitária e subjetiva. Para cumprir este intento, as ideias queer sobre identidade, sujeito, performatividade, performance e identificação são apresentadas e debatidas. Defende-se que a teoria queer é um verbo (ação) ao invés de um substantivo (identidade) e a aplicação de seus conceitos não se restringe somente aos estudos sobre gênero, sexualidade e minorias. Por fim, discute-se a expansão da utilização dos conceitos queer no estudo de outras formas hegemônicas de categorias identitárias presentes no mundo corporativo.

Palavras-chave: teoria queer; identidade; sujeito; performatividade; estudos organizacionais.

\begin{abstract}
Queer theory initially developed in the nineties in the social sciences and humanities, especially in literary and linguistic studies, and was later incorporated into organizational studies. However, despite its application to organizational studies there is a lack of debate about its concepts and meanings. Thus, this article aims to deepen and review the debate about the concepts and meanings related to queer theory, focusing on the concepts related to identity and subjectivity production. To fulfill this purpose queer concepts about identity, subject, performativity, performance and identification are presented and discussed. It is argued that queer theory is a verb (action) rather than a noun (identity) and the application of its concepts is not only restricted to studies on gender, sexuality and minorities. Finally, the paper discusses the expansion of the application of queer concepts to other forms of hegemonic identity categories present in the corporate world of work.
\end{abstract}

Key words: queer theory; identity; subject; performativity; organizational studies. 


\section{Introdução}

Os conceitos desenvolvidos pela teoria queer começaram a ser utilizados nos estudos organizacionais por Brewis, Hampton e Linstead (1997) com a publicação do artigo Unpacking Priscilla: Subjectivity and Identity in the Organization of Gendered Appearance. Entretanto, Brewis et al. (1997) não rotulam os conceitos utilizados em seu artigo com a denominação teoria queer, aliás, fato muito comum entre autores classificados como teóricos queer, conforme será visto mais adiante. Entretanto, a denominação teoria queer debutou pela primeira vez nos estudos organizacionais com a publicação por Parker (2001) de Fucking Management: Queer, Theory and Reflexivity, e, desde os seus primórdios, a teoria queer sempre proporcionou muitos debates entre estudiosos organizacionais, sendo que alguns destes foram promovidos por edições especiais de revistas como, por exemplo, a revista Gender, Work and Organization, organizada por Linstead e Brewis (2004), objetivando questionar as fronteiras identitárias dualistas e binárias de gênero presentes nos estudos organizacionais.

Essa teoria expandiu-se e tem sido utilizada no campo organizacional para estudar amizade no ambiente de trabalho (Rumens, 2008a, 2008b, 2010, 2012), liderança (Harding, Lee, Ford, \& Learmonth, 2011; Muhr \& Sullivan, 2013), subjetividade e identidade (Calás, Ou, \& Smircich, 2013; McDonald, 2013; Scurry, Rodrigues, \& Bailouni, 2013), beleza e embodiment (Gurrieri \& Cherrier, 2013), políticas de orientação sexual (Beckett, 2012; Thanem, 2010), gênero e performatividade (Baines, 2010a; Billing, 2011), humor (Kenny \& Euchler, 2012), temporalidade (Steyaert, 2015) e espaço (Tyler \& Cohen, 2010). Entretanto, apesar da aplicação de conceitos relacionados à teoria queer terem se consolidado nos estudos organizacionais nas últimas décadas, o debate acerca de seus conceitos e significados ainda necessita ser aprofundado. Portanto, existe uma lacuna acerca dos significados e da aplicação dos conceitos desenvolvidos pela teoria queer no campo organizacional.

Assim, este artigo busca cobrir parte dessa lacuna ao revisar o debate dos principais conceitos e significados da teoria queer relacionados à identidade. Objetiva-se com isso trazer à tona os principais conceitos da teoria queer relacionados à identidade. O estudo sobre identidade nos estudos organizacionais tem se intensificado nas últimas décadas (Du Gay, 2007; Pullen \& Linstead, 2005), entretanto, o estudo sobre identidades fundamentado em conceitos da teoria queer ainda permanece pouco explorado. Dessa forma, a primeira parte deste artigo começa abordando o surgimento da teoria queer, problematizando o que significa a expressão queer. Em seguida, os princípios que regem a concepção de sujeito e identidade na teoria queer são analisados com foco especial para a performatividade e os processos de identificação. Posteriormente, são evidenciados alguns cuidados sobre o uso nos estudos organizacionais do termo queer. Para concluir, o artigo debate o uso dos conceitos queer sobre identidade para outros aspectos da vida organizacional que não estão diretamente relacionados ao estudo de sexualidade e gênero ou de minorias.

\section{A Emergência da Teoria Queer}

Apesar da presença da teoria queer na academia brasileira em campos do saber como Psicologia (Borges, 2014; Chidiac \& Oltramari, 2004; Sampaio \& Germano, 2014), Filosofia (Rodrigues, 2012) e Literatura/Linguística (Costa \& Ávila, 2005), foi na Educação (César, 2009; Franco \& Cicillini, 2015; Motta \& Ribeiro, 2013) e na Sociologia (Alós, 2010; Brumer, 2009; Duque, 2012; Fernandes, 2015; Miskolci, 2009a; Miskolci \& Balieiro, 2011; Pino, 2007) que a teoria queer se consolidou. Quase a totalidade desses estudos desenvolvidos buscam analisar aspectos identitários sobre gênero e sexualidade (Alós, 2010; Borges, 2014; Brumer, 2009; César, 2009; Chidiac \& Oltramari, 2004; Duque, 2012; Fernandes, 2015; Franco \& Cicillini, 2015; Miskolci, 2009a; Miskolci \& Balieiro, 2011; Motta \& Ribeiro, 2013; Pino, 2007; Rodrigues, 2012; Sampaio \& Germano, 2014). Especificamente nos estudos organizacionais brasileiros, a teoria queer ainda não se encontra consolidada, como nos estudos organizacionais do Reino Unido. Apesar do crescimento numérico, nos últimos anos, no campo organizacional brasileiro de pesquisas sobre gênero (Andrade, Macedo, \& Oliveira, 2014), a teoria queer 
ainda é pouco utilizada pela área como aporte conceitual para esses estudos, sendo que a maioria das abordagens utilizadas ainda tem uma visão a-histórica sobre gênero e estão fundamentadas em abordagens feministas liberais e radicais (Souza, Corvino, \& Lopes, 2013). Portanto, poucos estudos organizacionais brasileiros utilizam a teoria queer como fundamento para suas análises, destacando-se, neste sentido, os estudos de Souza e Carrieri (2010), Souza e Pereira (2013), Souza e Carrieri (2015), Cerqueira e Souza (2015) e Souza, Bianco e Junquilho (2015).

A teoria queer emergiu primeiramente nas ciências humanas com estudos literários, linguísticos e discursivos, espalhando-se posteriormente para as ciências sociais (Cohen, 1997). Foram seminais no desenvolvimento da teoria queer os trabalhos de Sedgwick, Butler, Lauretis, Preciado, Rubin, Seidman, Warner, Halperin e Halberstan (Pino, 2007), trabalhos estes que fazem com que a teoria queer seja construída pelo encontro dos estudos culturais americanos com o pós-estruturalismo francês (Miskolci, 2007), tendo como principal objetivo questionar as concepções clássicas de sujeito e identidade. Entretanto, vale ressaltar que muitos autores responsáveis pelo desenvolvimento de conceitos e princípios rotulados como teoria queer nunca usaram a expressão teoria queer para definirem suas obras.

A expressão teoria queer foi primeiramente utilizada em 1990 por Teresa de Lauretis ao organizar uma conferência na Universidade da Califórnia denominada de Queer Theory (Warner, 2012). A principal intenção de Lauretis foi unir o termo queer, até então considerado um termo pejorativo, com a palavra teoria, tão sacralizada pelas ciências (Halperin, 2003). Lauretis (1991) também foi a primeira a publicar artigo acadêmico com a expressão teoria queer em seu título. Ao unir a palavra queer com o termo teoria, Lauretis pretendia problematizar e colocar em suspeição os conhecimentos científicos e teorias relacionadas a identidades gays e lésbicas. Em outras palavras, Lauretis intencionava tornar queer a teoria, ao invés de criar uma teoria (Halperin, 2003). Tornar a teoria queer é duvidar das verdades universais presentes nas teorias, problematizando todo conhecimento que se apresenta com o status de verdade universal por meio da análise e da evidenciação das relações de poder que produzem determinados saberes como hegemônicos. Por isso, a teoria queer não pode ser vista como sendo uma escola, doutrina, teoria ou teorização particular da vida humana, pois não existe teoria por trás da teoria queer (Halperin, 2003).

Por isso, a teoria queer deve ser entendida como um projeto sempre em construção, e seu futuro não pode jamais ser previsto (Warner, 1993). O significado de queer não pode ser solidificado e concebido como algo consistente; ao invés disso, indeterminação e elasticidade são suas características constituintes. Em outras palavras, a eficácia política da teoria queer depende de sua resistência à definição (Jagose, 1996), ou seja, a teoria queer resiste a qualquer definição (Philbrook, 2003). Portanto, teoria queer tem um significado sempre aberto, incompleto e inacabado. Mas, a incompletude, a abertura e inacabamento não constituem sua fraqueza, pelo contrário, eles afirmam sua força e sua capacidade de resistência ao hegemônico, ao normal. A teoria queer resiste a definições, e essa resistência deve ser sempre revisada exatamente para resistir às exclusões pelas quais o termo queer é mobilizado (Butler, 1993a).

Entretanto, apesar de sua resistência à definição, a teoria queer pode ser considerada como o estudo de relações de poder dentro de uma perspectiva foucaultiana (Seidman, 2006) e não faz o menor sentido considerar a teoria queer uma teoria, pois se a teoria queer suspeita de todas as metanarrativas, a própria teoria queer deve ser incluída nessa suspeição (Gamson, 2003). Além disso, a teoria queer não é um corpo unificado de conhecimento (Watson, 2005), fazendo com que Gardiner (2005) utilize a expressão teorias queer, no plural, exatamente para afirmar a heterogeneidade de abordagens e conceitos sob o rótulo teoria queer. Portanto, deve-se evitar cair na tentação de apresentar a teoria queer como algo unificado e totalmente coerente, com técnicas pré-definidas de como se fazer uma pesquisa (Watson, 2005), pois isso manifesta a tendência da palavra teoria prevalecer sobre o termo queer, atuando como uma forma de domesticação da teoria queer (Halperin, 2003). Assim, a teoria queer não é uma teoria somente porque ela não tem um corpo sólido, unificado e consistente, mas exatamente porque, para ser efetiva em seu propósito, precisa resistir às forças que a querem estabilizar e normalizar. O importante é tornar queer a teoria ao invés de teorizar o queer (Jagose, 1996). Assim, exatamente para 
enfatizar que a teoria queer não é uma teoria, Souza e Carrieri (2010) preferem utilizar a denominação analítica queer ao invés de teoria queer, ou seja, não existe uma teoria queer, mas, sim, analíticas queer.

O processo de transformação da teoria queer em teoria deve ser entendido como um processo de normalização da teoria queer, processo este que objetiva torná-la mais suave e branda, fazendo com que não possa realizar seu principal objetivo que é oferecer alternativas a sistemas hegemônicos (Halberstam, 2011) e, dessa forma, problematizar o normal (Halperin, 1995; Jagose, 1996; Miskolci, 2009b). Portanto, a teoria queer é por definição a problematização do normal, do legítimo e do dominante (Halperin, 1995). A teoria queer refere-se às lógicas e às formas de organização não normativas em um determinado tempo e espaço (Halberstam, 2005), e render o termo queer à teoria é um processo que a incapacita de criticar as normas e o normal. Em outras palavras, o processo de normalização da teoria queer a desabilita a questionar o fundacional, o normal e o hegemônico (Turner, 2000), sendo esse processo exatamente o movimento oposto pelo qual Lauretis uniu as palavras queer com teoria, pois o termo queer afirma transgressão e resistência ao normal (Watson, 2005).

Assim sendo, a teoria queer é apenas um conjunto de especulações intelectuais coletivas e não um corpo unificado de conceitos e metodologias, devendo ser considerada como um conjunto de princípios e não como uma teoria (Bryant, 2003). A teoria queer manifesta princípios que colocam em cheque as noções hegemônicas e estáveis de identidades (Sullivan, 2003), sendo a principal preocupação da mesma o conceito de ser humano forjado pelo iluminismo/humanismo. A teoria queer é um ataque e uma resposta ao universalismo, ao binarismo e ao essencialismo presentes na concepção de sujeito do iluminismo/humanismo (Souza \& Carrieri, 2010). Entender esses princípios é uma tarefa importante para se entender a teoria queer e, assim sendo, o próximo tópico deste artigo abordará esse tema.

\section{Identidade na Teoria Queer}

Muitos dos escritos queer dedicam-se a problematizar a produção identitária relacionadas a gênero e sexualidade. Assim, para compreender o significado de identidade na teoria queer trabalhos relacionados a gênero e sexualidade serão aqui abordados. Em relação à sexualidade, a teoria queer a concebe como socialmente e culturalmente criada, historicamente variável, e uma questão política ao invés de biologicamente determinada, como se pertencesse à esfera da natureza ou fosse uma mera questão de escolha pessoal (Butler, 1990; Edwards, 2005; Jagose, 1996; Sedgwick, 2008; Seidman, 1996; Sullivan, 2003). Entretanto, o que difere a teoria queer de outras abordagens culturais é que o ponto principal para a teoria queer não é somente focar na construção cultural da sexualidade, mas analisar as formas pelas quais o poder é assimetricamente atribuído entre e dentro das categorias sexuais (Cohen, 1997). Por isso que a teoria queer é uma abordagem construcionista social que desafia os entendimentos essencialistas e universalistas de identidade, enfatizando a sexualidade, e qualquer outra forma de identidade, como um princípio organizador, político e social (Seidman, 1996).

Com isso, a teoria queer intenciona mostrar como identidades sexuais binárias (homossexual e heterossexual) são construções discursivas sociais, históricas e culturais envoltas por relações de poder e saber, desafiando o conceito hegemônico e tido como natural pelo qual heterossexuais e homossexuais são vistos como produtos biológicos que pertencem à ordem da natureza. Assim, identidades são vistas com produto de relações de poder e saber (Seidman, 2006). Para a teoria queer, o discurso atua de uma forma normativa moldando fronteiras e construindo identidades e hierarquias entre as categorias identitárias. Entretanto, a teoria queer refuta que esse processo de normalização seja determinístico e fundamentado em uma concepção estática e estável de identidade. As identidades são sempre construídas e contidas por múltiplas práticas de categorizações e regulações, as quais as tornam fluidas, heterogêneas, políticas e até mesmo paradoxais (Cohen, 1997; Lovaas \& Jenkins, 2007). A teoria queer acredita que as identidades são sempre múltiplas e atravessadas por diversas outras identidades, como orientação sexual, raça, classe social, nacionalidade, gênero, idade (King, 2016) dentre outras, que se interceptam e/ou combinam-se. Portanto, todas as formas de identidades funcionam como forças políticas disciplinadoras e organizadoras. 
Entretanto, apesar dos afetos, entre as diversas formas de identidades, vale salientar que o sujeito não é uma soma ou um número determinado de identidades-base. Acreditar em um modelo aditivo de identidade é afirmar que o sujeito é uma soma de identidades-base que existem simplesmente independentes, lado a lado, uma das outras (Sullivan, 2003), ou seja, identidade não é uma soma de caixas ou cubículos que existem sem ligação uns com os outros, como sexualidade, gênero, raça e classe social. Identidade é um fluxo entre esses diversos aspectos, ou seja, identidade é um processo (Anzaldúa, 1991).

O modelo aditivo de identidade não considera o caráter complexo, múltiplo e até mesmo contraditório das subjetividades. Ele não explica porque ser posicionado como homem negro homossexual é significantemente diferente de ser posicionado como homem negro heterossexual. Além disso, não se pode afirmar que o homem negro homossexual é duplamente oprimido por ser negro e homossexual, enquanto que o homem branco heterossexual seria apenas singularmente oprimido por ser negro. A experiência vivida pelos sujeitos são significativamente diferentes, pois raça e sexualidade, entre outros componentes, inflectem e/ou infundem uma na outra de uma forma não determinística e imprevisível (Sullivan, 2003). Portanto, identidades sexuais e raciais são sistemas de significado e entendimento que atuam juntos em um processo autoformativo em que a raça atua, define e constitui a sexualidade, e vice-versa (Barnard, 1999). Com isso, a teoria queer destrói as noções de que o sujeito é autônomo e que tem um self coerente, como também não acredita que o sujeito é uma coleção de diversas identidades que existem e atuam em caixas isoladas e autônomas (Gamson, 2003).

Desta forma, identidades são discursivamente constituídas por processos contínuos, ou seja, em movimentos constantes e ininterruptos de construção e desconstrução pelos quais as diversas expressões identitárias possíveis constituem-se por meio de afetos simultâneos, conjuntos e múltiplos, sem hierarquia entre elas, o que significa afirmar que não há uma identidade que existe a priori das demais ou que atue como base para outras identidades. Assim, não se pode afirmar que o sujeito é apenas um determinado número de identidades bases, como, por exemplo, deficiente, indígena, operária e mãe lésbica, e nem que, nesse exemplo específico, esse sujeito seria quatro vezes oprimido (Sullivan, 2003). Essa lógica aditiva de opressão não reconhece as implicações e intersecções entre essas identidades e nem que ser posicionado em uma identidade específica acima das demais é significativamente diferente de ser posicionado em outra. Identidades são performativas e instáveis, e não faz sentido supor que identidades entre sujeitos classificados em categorias idênticas sejam iguais (McDonald, 2013). Todas as identidades são fluídas, e o produto dos diversos elementos que as constituem não pode ser previsto de antemão.

Entretanto, a teoria queer não abandona o uso de categorias identitárias, mas busca manter essas categorias permanentemente abertas e seus significados contestáveis de acordo com o papel político que exercem (Seidman, 1996). Somente considerando as identidades múltiplas, processuais, políticas, abertas e instáveis é que outras formas de subjetividades e existências podem emergir. Por isso que a crítica ao sujeito é central para o ativismo da política queer (Butler, 1993a). Portanto, a teoria queer não é contrária ao uso de categorias identitárias, mas declara que "por mais que os termos de identidade devam ser usados ... essas mesmas noções devem tornar-se sujeitas às críticas das operações de exclusão que elas mesmas produzem" (Butler, 1993a, p. 19, tradução nossa). O que Butler (1993a) quer afirmar é que o problema não é o uso de termos que denominam ou expressam determinadas categorias identitárias, como homossexual, heterossexual, homem, mulher, dentre outros, mas o que ela crítica é o uso desses termos como se representassem categorias universais, essenciais, a-históricas, apolíticas e estáveis, não se trazendo para o debate as exclusões que tais categorias produzem. Por isso que Butler (1993a, p. 21, tradução nossa) afirma que "identidade é um erro necessário".

Entretanto, a desconstrução política de categorias identitárias "não deve paralisar o uso de tais termos, mas, idealmente, estender suas extensões, fazendo-nos considerar a que expensas e para quais propósitos os termos são usados, e através de quais relações de poder tais categorias têm sido forjadas" (Butler, 1993a, p. 20, tradução nossa). Teoria queer é a desestabilização e não a destruição ou o abandono do uso de categorias identitárias. Contudo, para atingir esse intento não é somente necessário reconceitualizar os conteúdos das categorias identitárias, mas sempre considerar a natureza interseccional e política das próprias identidades (Cohen, 1997), pois identidade é um local não fixo de 
lutas, engajamentos e contestações (Jagose, 1996), ou seja, identidade é um processo contínuo, sempre em construção e desconstrução. Assim, desnaturalizar e desconstruir identidades não é minimizar a significância das categorias em si, mas problematizá-las, historicizá-las e contextualizá-las ao invés de considerá-las naturais, universais ou simples termos descritivos (Jagose, 1996). Contudo, a desconstrução de categorias identitárias somente pode ser feita com a desconstrução do sujeito Iluminista/Humanista universal (Butler, 1993a).

Identidades são problemáticas porque são embebidas em vários paradoxos sobre a nossa percepção do self e nosso reconhecimento dos outros, fazendo com que a identidade seja algo coletivo, mas, que ao mesmo tempo, aproxima e separa sujeitos (Weeks, 1995). Para a teoria queer, a estrutura jurídica, a linguagem e a política constituem e limitam a matriz contemporânea de poder, e não há posição fora dessa matriz; entretanto, há a possibilidade de uma crítica genealógica de suas próprias práticas legitimadoras. Portanto, a tarefa mais importante para a teoria queer é formular, dentro dessa matriz contemporânea de poder, uma crítica das categorias de identidade que a linguagem e as estruturas jurídicas engendram, naturalizam e imobilizam (Butler, 1990). O importante para a teoria queer é mobilizar a proliferação subversiva das "categorias constitutivas que buscam manter gênero [ou qualquer outra forma de identidade] em seu lugar ao posicioná-lo como uma ilusão fundacional de identidade" (Butler, 1990, p. 46, tradução nossa).

Desta forma, a teoria queer valoriza a historicidade e a contingência de uma determinada identidade exatamente para deixá-la ser derrotada por aqueles sujeitos que são excluídos pelo mesmo termo que é empregado para definir e delimitar as fronteiras dessa identidade, mas sujeitos estes que, ao mesmo tempo, também esperam ser representados por essa identidade (Butler, 1993a). Assim, as identidades não são universais, unificadas, essenciais, estáveis e binárias. A teoria queer repudia as categorizações binárias ao enfatizar o caráter interseccional, fragmentado, complexo e múltiplo das identidades. A afirmação de que a teoria queer combate o sujeito universal e binário Iluminista/Humanista, e nos remete a outras questões: o que é o sujeito para a teoria queer? Por quais processos o indivíduo se constitui como sujeito? Assim, a próxima sessão pretende responder a essas questões ao debater o que é sujeito para a teoria queer.

\section{Sujeito, Identificação e Performatividade}

Para a teoria queer, a ideia de que sujeitos e objetos têm autonomia por meio de autonomeação pelo discurso é um conceito presentista forjado pelo Humanismo. Um conceito presentista acredita que o sujeito chega ao mundo e, no discurso, sem uma história, ou seja, o sujeito se constitui pela capacidade que o mesmo traz consigo para nomear a si mesmo e os outros, na qual a linguagem expressa apenas um desejo ou escolha individual ao invés de uma complexa história constitutiva de poder (Butler, 1993a). A teoria queer rompe com essa concepção voluntarista de sujeito, enxergando-o sempre como provisional, circunstancial, fragmentado e contingenciado pelos discursos (Miskolci, 2009b).

Desta forma, a principal tarefa genealógica é examinar as formas randômicas, provisionais e descontínuas pelas quais o poder funciona, analisando como resultado as formas de identidade/subjetividade que são discursivamente construídas (Sullivan, 2003). As concepções fundacionistas, voluntaristas e presentistas de sujeito são meras ficções (Butler, 1990). Autores queer (Butler, 1990, 1993a, 1993b; Halperin, 1995; Jagose, 1996; Sedgwick, 2008; Seidman, 1996) declaram que o sujeito não é o executor do executado, nem a origem da matriz de poder ou de uma ação específica exatamente para evitar o conceito voluntarista de sujeito presente no Iluminismo/Humanismo. O sujeito não é livre para decidir e agir fora das próprias relações de poder e discursos que o constituem como sujeito. Pelo contrário, são os processos de nomeação e categorização que operam pelo discurso que produzem alguém como um sujeito viável. Portanto, o discurso "tem uma história que não somente precede, mas condiciona seus usos contemporâneos, e ... esta história efetivamente descentra a visão presentista de sujeito como a origem exclusiva e proprietário do que é dito" (Butler, 1993a, p. 19, tradução nossa). Onde se vê um Eu proferindo ou falando algo, há primeiramente um discurso que 
habilita e permite que esse Eu fale, portanto, "não existe um 'Eu' que está por trás do discurso e executa sua vontade ou deseja através do discurso" (Butler, 1993a, p. 18, tradução nossa). Por isso que

paradoxalmente, a condição discursiva de reconhecimento social precede e contingencia a formação do sujeito: reconhecimento não é conferido pelo sujeito, mas forma o sujeito. Além disso, a impossibilidade de completo reconhecimento, ou seja, de cada vez habitar totalmente o nome pelo qual a identidade social de alguém é inaugurada e mobilizada, implica na instabilidade e incompletude da formação-sujeito (Butler, 1993a, p. 18, grifos originais, tradução nossa).

Dessa forma, o sujeito não está livre ou fora das normas discursivas, mas ele é produzido pela constante repetição dessas normas, ou seja, são essas normas que transformam os indivíduos em sujeitos (Butler, 2004). Assim, liberdade, possibilidade e agência do sujeito não têm um status abstrato ou présocial, mas são renegociadas a todo tempo dentro de uma matriz de poder (Butler, 1993a). Os indivíduos são ligados a uma identidade em um processo de identificação, ou seja, os indivíduos são compelidos pelas normas discursivas a identificarem-se na ordem simbólica, buscando por um reconhecimento compulsório nessa ordem para tornarem-se sujeitos. Devido a isso, sem reconhecimento no discurso, "é impossível existir como um ser humano" (Lee, Learmonth, \& Harding, 2008, p. 151) e as normas que permitem reconhecimento produzem, ao mesmo tempo, categorias de sujeitos normais e anormais. Portanto, normas são "categorias percebidas como tão naturais que frequentemente é difícil reconhecêlas" (Lee et al., 2008, p. 153).

Entretanto, a identificação em elementos da ordem simbólica nunca é completa (Kenny, 2012). Para o sujeito, a ordem simbólica apresenta-se como possuindo estabilidade, unidade e certeza, mas, de fato, ela é repleta de discrepâncias e instabilidades. Em consequência dessas discrepâncias e instabilidades, a ordem simbólica produz um self sempre dividido, incompleto e em constante luta. Devido à incompletude do self, o sujeito falha em conseguir o completo reconhecimento, compelindoo sempre a estar constantemente buscando e desejando o reconhecimento, ao mesmo tempo em que essa busca declara a impossibilidade de realização do sujeito. Entretanto, o sujeito não tem a opção de existir fora da ordem simbólica e, apesar das falhas para realizar o reconhecimento, é melhor existir em subordinação a essa ordem do que não existir como sujeito (Kenny, 2012; Lee et al., 2008).

Por isso que, em relação a identidades de gênero, Butler (1993a, p. 23, tradução nossa) afirma que "feminilidade não é o produto de uma escolha, mas a forçosa citação de uma norma, pelas quais a historicidade complexa é indissociável das relações de disciplina, regulação, punição". A autora ainda declara que, de fato, "não existe 'sujeito' que assume uma norma de gênero. Pelo contrário, essa citação de normas de gênero é necessária para qualificar-se como 'sujeito', para tornar-se viável como 'sujeito"” (Butler, 1993a, p. 23). Em outras palavras, identificação não é um ato deliberado do sujeito ou uma escolha consciente. Não é o sujeito que se identifica com algo, mas é a repetição das normas que compele, conduz e obriga o indivíduo a se identificar com a ordem simbólica para que o mesmo possa existir como sujeito. Assim, a performatividade, processo pelo qual as normas são constantemente repetidas, merece um destaque especial e será aqui analisada.

O desejo por reconhecimento suporta a performance do sujeito na teoria queer (Tyler \& Cohen, 2008). A construção de categorias que organizam a identidade demanda um processo contínuo e repetitivo de recitação que produz categorias como biologicamente, linguisticamente ou socialmente naturais, pois as "repetições compulsórias que governam a identidade são uma forma de regulação social, os vários atos da identidade não são expressivos, mas performativos" (Tyler \& Cohen, 2008, p. 117, tradução nossa) e, porque os atos são constantemente repetidos, as identidades recitadas aparecem como naturais. Entretanto, a repetição não é performada pelo sujeito, mas é a repetição que "inicia o indivíduo para o status sujeitado de sujeito" (Butler, 1993b, p. 121). Mas, nesse processo, o sujeito "não somente recebe reconhecimento, mas alcança também uma certa ordem de existência social em ser transferido de uma região exterior de indiferente, questionável, ou impossível ser para o domínio discursivo ou social de sujeito" (Butler, 1993b, p. 121, tradução nossa).

Portanto, performatividade não é um ato singular ou deliberado do sujeito. Performatividade não é um ato intencional ou consciente de uma pessoa e não tem suas origens em alguém, pelo contrário, 
seus fundamentos estão no poder vinculado relacionado ao discurso. O sujeito emerge no mundo que tem normas culturais, históricas e sociais que circulam por meio do discurso. Esses discursos manifestam a matriz de inteligibilidade e eles atuam com um background que forja o sujeito pelas práticas sociais constantemente repetidas. Assim, performatividade é construída pela repetição de um conjunto específico de práticas. $\mathrm{O}$ conceito de performatividade torna-se mais fácil de compreender quando o materializamos em uma categoria identitária específica, como gênero, conforme se diz a seguir:

Gênero é performativo na medida em que é o efeito de um regime regulatório das diferenças de gênero em que os gêneros são divididos e hierarquizados sob restrições. Restrições sociais, tabus, proibições, ameaças de punição operam na repetição ritualizada de normas, e essa repetição constitui a cena temporalizada de construção e desestabilização de gênero. Não há sujeito que precede ou promulga esta repetição de normas. Na medida em que essa repetição cria um efeito de uniformidade de gênero, um efeito estável de masculinidade ou feminilidade (Butler, 1993a, p. 21).

Portanto, performatividade funciona como uma rede de premiações e punições que confere e afirma um poder vinculado sobre a ação performada que acontece e é operada por meio do discurso. Na citação anterior, gênero é performativo não porque é algo que o sujeito deliberadamente e divertidamente assume, mas porque através da sua reiteração ele consolida o sujeito, ou seja, performatividade é a pré-condição do sujeito (Jagose, 1996). Assim, performatividade é a pré-condição que constitui e produz a ação do sujeito. Em outras palavras, "performatividade não é nem um jogo livre e nem uma auto representação teatral, nem pode ser simplesmente equiparada com performance" (Butler, 1993b, p. 95, tradução nossa). Portanto, a performatividade não pode ser reduzida à verdade psicológica interna e escondida ou a uma aparência externa (Butler, 1993a). Essa é exatamente a diferença entre performatividade e performance, abaixo exemplificadas:

Em nenhum sentido pode-se concluir que a parte do gênero que é performada é, portanto, a 'verdade' do gênero; performance como 'ato' vinculado é distinguido de performatividade na medida em que esta última consiste em uma reiteração de normas as quais precedem, compelem, excedem o performador [executor da ação] e nesse sentido não pode ser tomado como fabricada pelo 'desejo' ou 'escolha' do performador; além disso, o que é 'performado' funciona para esconder, se não repudiar, o que permanece opaco, inconsciente, imperformável. A redução da performatividade para performance seria um erro (Butler, 1993a, p. 24, tradução nossa).

Portanto, a performatividade não são as normas em si ou a origem das mesmas, mas precisa ser pensada simplesmente como o processo que regula a repetição de normas (Butler, 1993b), sendo que essa repetição não é performada pelo sujeito. Repetição é o que permite, capacita e produz o sujeito. Performatividade, por sua vez, não é um ato singular performado por um sujeito, mas a condição temporal para o sujeito existir, ou seja, é o processo pelo qual o sujeito é constituído como sujeito pela reiteração de normas. Comportamentos e ações parecem ser reais, normais e naturais porque o sujeito é performativamente induzido a realizar performances de acordo com as normas e as convenções sociais (Lovaas \& Jenkins, 2007).

A performatividade é construída por ficções regulatórias que ordenam e organizam nossas vidas ao mesmo tempo em que tornam possível o ordenado e o organizado serem considerados naturais e corretos (Lee et al., 2008). Em outras palavras, performatividade regula a repetição de normas discursivas que são vistas como seu produto, mas que de fato não são seu produto. Pelo contrário, as normas são o que constituem e permitem a performatividade existir (Butler, 1993a). Devido a isso, as normas que regulam as condições e as possibilidades pelas quais o sujeito pode emergir como sujeito oferecem para o indivíduo as possibilidades de categorias identitárias que são reconhecíveis e possíveis em um determinado tempo e espaço. Enfim, a performatividade constitui as possíveis performances que podem ser promulgadas em um contexto específico.

Entretanto, a necessidade de constante repetição das normas na construção do sujeito demonstra exatamente a ineficácia dessas normas. Ninguém segue completamente a performatividade requerida pelas normas e, conforme dito anteriormente, sempre há a impossibilidade de alguém reconhecer-se 
completamente na inteligibilidade da ordem simbólica produzida pela matriz de poder, afirmando ainda mais a instabilidade e a incompletude do sujeito. De fato, as práticas compulsórias constantemente reiteradas pela performatividade são reguladas por normas, mas essas normas não podem ser concebidas como determinísticas na formação do sujeito. Por isso, é impossível que a repetição de uma ação ocorra da mesma forma que antes performada (Sullivan, 2003).

Apesar da constante citação repetida de normas, uma performance sempre escapa de sua identidade ideal porque "a performance contínua de identidade envolve meramente uma citação repetida de, ou um 'objetivo de' uma ideia de um estado ideal, que realmente não existe" (Kenny \& Euchler, 2012, p. 310), ou seja, performance é uma fantasia de uma fantasia (Butler, 1990). Exatamente por isso, todas as performances demonstram a contingência da identidade e o potencial de mudança e subversão contida no que é performado. Performance não é uma ato mimético ou uma (re)encenação, pois toda repetição é instável e abre a possibilidade de subversão da matriz de poder com sua lógica de inteligibilidade. Portanto, uma identificação específica já traz consigo suas instabilidades e riscos, ou seja, toda relação de poder traz consigo suas possibilidades de resistência e subversão, o que prova que as possibilidades de subversão não são externas a ela.

Portanto, a teoria queer não considera que o sujeito seja passivo ou determinado por uma matriz de poder. A constante recomposição da subjetividade não é um processo determinístico e nem uma soma de identidades cristalizadas. Em outras palavras, nos processos de subjetivação, a subjetividade produzida pode escapar de seus impasses repetitivos e determinísticos, pois os sujeitos não são apenas recipientes passivos na construção de suas identidades, mas são agentes ativos, embora frequentemente inconscientes, por meio de suas práticas (Lovaas \& Jerkins, 2007). Contudo, apesar dessa falha em toda matriz de poder, para as pessoas existirem como seres humanos, elas são forçadas a identificarem-se de acordo com as normas sociais que produzem identidades. Somos a todo tempo compelidos a buscar uma identificação para escapar da dor e da violência associadas ao ser deixado de fora das categorias normativas (Kenny \& Euchler, 2012).

O fato da teoria queer ter uma forte relação com o estudo de identidades, principalmente identidades desvalorizadas pela matriz de inteligibilidade contemporânea, tais como mulheres, homossexuais, transgêneros e negros; faz com que muitas vezes o termo queer seja erroneamente interpretado como sendo uma identidade sexual específica ou significando minorias. É este ponto que o próximo tópico esclarece.

\section{Queer Não É uma Identidade}

Devido à estrita relação que a teoria queer tem com o estudo de sexualidade, é comum muitos trabalhos organizacionais usarem o termo queer como significando identidade sexual. Sob este aspecto, tais estudos usam a palavra queer de três maneiras: (a) um termo guarda-chuva, que representa todos os tipos de sexualidades presentes no acrônimo LGBT (Lésbicas, Gays, Bissexuais e Transgêneros) (Adams, 2012; Baines, 2010b; Litvin, 2008; Richardson \& McGlynn, 2011; Rosenbaum, Walsh, \& Wozniak, 2012; Schmidt, Githens, Rocco, \& Kormanik, 2012); (b) significando uma nova identidade sexual específica representada pela letra Q na sigla LGBTQ (Lésbicas, Gays, Bissexuais, Transgêneros e Queer) (Hill, 2009; Kesetovic, 2009; Taylor, Mallinson, \& Bloch, 2008; Willis, 2012); ou (c) as duas maneiras ao mesmo tempo (Gates, 2012).

A teoria queer tem sido usada inapropriadamente como sinônimo de qualquer abordagem intelectual que estuda gays, lésbicas, travestis, transexuais, drag queens e kings (Quinn \& Sinfield, 2006), significando qualquer estudo sobre minorias sexuais. Contudo, isto é um equívoco porque a teoria queer não estuda somente sexualidades e nem todos os estudos sobre sexualidades têm relação com a teoria queer. Para que um estudo sobre sexualidade seja considerado queer, é necessário principalmente que ele seja fundamentalmente transgressivo as normas e a inteligibilidades hegemônicas (Quinn \& Sinfield, 2006), pois a teoria queer interroga a relação entre desejo e identidade, ou seja, ela está 
primeiramente interessada em problematizar como categorias sexuais passam a ser consideradas identidades estáveis (Watson, 2005).

Portanto, a teoria queer não pode ser vista como o estudo de uma população gay ou lésbica, por exemplo. A teoria queer problematiza os processos de categorizações sexuais, enfatizando suas desconstruções e não o estudo de uma população específica, principalmente porque as pesquisas que estudam populações presumem que a população estudada tem uma identidade estável e fixa que se manifesta em seus participantes (Seidman, 1996; Watson, 2005), algo que a teoria queer repudia ao considerar as identidades fragmentadas e incompletas. Além disso, o fato de que, nos Estados Unidos, o modelo patrão a ser seguido para todas as minorias é o modelo racial ou étnico contribui ainda mais para a construção de um modelo de diversidade sexual baseado no conceito de populações raciais ou étnicas universais e estáveis (Warner, 1993). Entretanto, a teoria queer enfatiza os múltiplos sistemas de opressão que estão em operação e questiona como esses sistemas utilizam categorias e identidades institucionalizadas para regular e socializar os sujeitos (Cohen, 1997).

Assim, a teoria queer não pode ser entendida como sendo apenas o estudo de minorias. Queer é uma abordagem política ao invés de uma identidade inata e natural de gays, lésbicas, negros, mulheres, dentre outras (Halperin, 1995). Para que a teoria queer mantenha seu potencial radical, a palavra queer precisa ser entendida como um termo crítico ao invés de ser meramente solidificado como sendo um novo rótulo, categoria ou identidade aceitável (Jagose, 1996). Em outras palavras, a teoria queer não estuda somente minorias, mas, ao invés disso, ela é "um estudo de todos os saberes e práticas sociais que organizam a 'sociedade' como um todo" (Seidman, 1996, p. 13).

Para evitar os problemas da associação do termo queer com uma identidade específica, é necessário pensar a teoria queer como um verbo (ações) ao invés de um substantivo (identidades). Em outras palavras, a teoria queer é um verbo, um projeto de ação política, e não apenas o estudo de minorias ou uma identidade específica (Johnson, 2008; Sullivan, 2003). Queer não é uma nova gíria para gays, lésbicas, bissexuais e transgêneros, ou seja, queer não é um novo rótulo para velhas caixas de identidades ou um grande termo guarda-chuva que abarcaria todas as sexualidades contidas no termo LGBT. "Neste sentido, queer precisa ser entendido como uma prática desconstrutiva que não é efetuada por um sujeito já constituído, e que, por sua vez, não suprirá o sujeito com uma identidade nomeável" (Sullivan, 2003, p. 50).

Portanto, queer não é uma nova identidade sexual específica ou um termo guarda-chuva para todas as minorias sexuais. É óbvio que a teoria queer é uma abordagem apropriada para se analisar quaisquer formas de identidades que são categorizadas pelas relações de poder e saber como minorias. Entretanto, isto não significa que a teoria queer deva ser considerada uma abordagem que estude somente minorias, pois a teoria queer tem o potencial de estudar tanto o que é considerado anormal quanto normal (Sedgwick, 2008). Neste sentido, a teoria queer é uma abordagem apropriada para estudar as práticas que organizam a sociedade como um todo. Para que a teoria queer mantenha seu potencial crítico ela necessita acumular múltiplos significados e não ser apenas "uma forma resumidamente útil de falar sobre todas as experiências gays, lésbicas, bissexuais e transgêneros" (Seidman, 1996, p. 11, tradução nossa).

De fato, usar o termo queer como uma caixa identitária ou um guarda-chuva que significaria somente minorias reforça, "ao invés de desconstruir, as formas pelas quais identidade e diferença são construídas em termos de oposições binárias, de nós e eles - oposições às quais nunca são neutras, mas são sempre hierárquicas" (Sullivan, 2003, p. 45, tradução nossa). Além disso, conforme já salientado, outro problema em usar a teoria queer como uma caixa ou guarda-chuva para identidades sexuais faz com que o termo queer seja equivocadamente entendido como uma identidade (substantivo) ao invés de um verbo ou de uma ação política.

Assim, entender queer como uma identidade sexual é estabilizar categorias identitárias e reforçar a binariedade entre elas ao invés de desestabilizá-las (Cohen, 1997). Portanto, quando queer é usado como significando, um grande guarda-chuva para gays, lésbicas, transexuais, travestis e drags "reforça simples dicotomias entre heterossexuais e tudo 'queer'. Um entendimento sobre as formas pelas quais 
o poder informa e constitui sujeitos privilegiados e marginalizados em ambos os lados desta dicotomia permanece não examinada" (Cohen, 1997, p. 438, tradução nossa). Por isso que, na teoria queer, a análise dos processos de normalização não está apenas relacionada com a produção do anormal, mas também com a produção do normal, procurando desafiar qualquer forma de identidades normativas (Sullivan, 2003). As categorias normal e anormal resultam de processos de normalização e ambas precisam ser problematizadas e, sendo a teoria queer uma analítica dos processos de normalização, é necessário não apenas estudar identidades que aparentemente rompem com as normas, mas focar nos processos de normalização que simultaneamente produzem o hegemônico e o subalterno, o normal e o anormal (Miskolci, 2009b).

Portanto, queer não significa um novo nome para gays ou lésbicas, ou seja, queer não é uma caixa nova para velhas identidades. Queer também não é um termo guarda-chuva para um conjunto de minorias sexuais expressas no acrônimo LGBT. Aliás, queer não se restringe ao estudo de sexualidades culturalmente consideradas anormais, mas analisa tanto identidades estabelecidas como normais e anormais. Além disso, o mais importante é que queer estuda qualquer forma de produção identitária, não se restringindo somente a identidades sexuais. A capacidade dos conceitos da teoria queer serem aplicados a diversas outras formas de identidades faz dela uma abordagem com potencial de aplicação, inclusive em identidades organizacionais, aspecto este que será salientado a seguir nas conclusões deste artigo.

\section{Queering Identidade nos Estudos Organizacionais: Algumas Considerações Finais}

Após terem-se debatido os significados da teoria queer e os principais conceitos sobre identidade, sujeito, identificação e performatividade nos estudos queer, resta enfatizar as contribuições para os estudos organizacionais sobre o uso desses conceitos relacionados à pesquisa sobre identidade. Para cumprir esse intento, duas contribuições/aplicações da teoria queer pouco explorados pelos estudos organizacionais de identidades são salientadas: (a) análise sobre identidades hegemônicas; e (b) estudos de outras formas identitárias que não estejam diretamente relacionadas a sexualidade e gênero.

Conforme demonstrado, a teoria queer tem como ponto central problematizar todas as categorias de identidades (Turner, 2000) e não somente identidades culturalmente consideradas minoritárias. A teoria queer preocupa-se com os processos de normalização que produzem, em uma lógica binária, tanto o normal quanto o anormal. Portanto, é necessário que os estudos organizacionais expandam as fronteiras e os limites do uso da teoria queer para além do estudo de minorias, como gays, lésbicas, transexuais, negros e mulheres, pesquisando também identidades hegemônicas. Os estudos organizacionais não podem limitar o uso da teoria queer a apenas o estudo de minorias, mas, por meio desses conceitos, podem-se analisar identidades hegemônicas naturalizadas como padrão e normais, tais como heterossexuais, homens e caucasianos, dentre outras.

Somente procedendo dessa forma, a lógica binária nós-eles pode ser interrompida. Todas as formas de identidades necessitam ser entendidas como dispositivos de poder que organizam a sociedade por meio do estabelecimento de sistemas hegemônicos de lógica binária sobre o que é normal e o que é anormal, construindo categorias discursivas, identidades e hierarquias entre sujeitos. Em outras palavras, a teoria queer "nos oferece um método para imaginar, não alguma fantasia de um lugar qualquer, mas alternativas aos sistemas hegemônicos existentes" (Halberstam, 2011, p. 89, tradução nossa). Exatamente devido ao senso comum depender profundamente desses sistemas hegemônicos para produzir normas e, consequentemente, o normal e o anormal, a teoria queer não pode se restringir apenas ao estudo de categorias anormais de sujeitos produzidas por esses sistemas, mas deve ser estendida a todas as formas de identidades produzidas. Somente procedendo-se dessa maneira, os sistemas hegemônicos com suas lógicas binárias podem ser problematizados e interrompidos.

Sendo identidade um processo de identificação e desidentificação na busca por reconhecimento em categorias identitárias discursivamente construídas, as identidades são categorias de saber e poder 
operadas pelo discurso nas quais a linguagem trabalha como um processo normativo que molda subjetividades (Seidman, 1996). Neste sentido, o conceito de identidade presente na teoria queer pode ser estendido para identidades laborais, ou seja, identidades profissionais construídas no ambiente laboral. "Como [a teoria] queer não é alinhada a nenhuma categoria de identidade específica, ela tem o potencial para ser anexada de forma rentável para qualquer número de discussões" (Jagose, 1996, p. 2, tradução nossa). Portanto, a teoria queer "retém, ... um potencial único como um lugar necessariamente não fixo de comprometimentos e contestações" (Jagose, 1996, p. 129, tradução nossa) e expandir o potencial de contestação identitária para problematizar identidades consideradas naturais, normais e estabelecidas é o principal objetivo da teoria queer.

Assim, a teoria queer "descreve um horizonte de possibilidade que sua extensão precisa e escopo heterogêneo não pode em princípio ser delimitado antecipadamente" (Halperin, 1995, p. 62) e, estando a teoria queer no campo magnético da identidade, todas as formas de identidades devem ser vistas como construídas e contidas por múltiplas práticas de categorização e regulação (Cohen, 1997) e, como sendo fluídas, heterogêneas, políticas e até mesmo paradoxais (Lovaas \& Jenkins, 2007) em um eterno vir a ser (becoming). Portanto, os conceitos queer relacionados a identidade, performatividade, identificação e performance podem ser aplicados a estudos relacionados à construção de identidades no trabalho. Sobre isto, tornar-se um gerente ou um operário precisa ser entendido como um processo de identificação discursiva pelo qual a construção da identidade é permeada pela constante repetição de normas (performatividade) que moldam as performances de gerentes e trabalhadores. Essas identidades não são fixas e estáveis, mas são fragmentadas e acabam funcionando em uma lógica binária que produz hierarquias dentro das organizações e estabelecem tanto o que é um gerente e um trabalhador normal/padrão ou anormal em tempo e lugares específicos. Problematizar estas identidades é também problematizar a lógica capitalista, rompendo com noções funcionalistas de identidades laborais naturais e apolíticas.

Portanto, a teoria queer traz novas possibilidades para analisar as normas culturais e organizacionais que produzem identidades laborais, pois ao "desafiar a ontologia da sexualidade a QT [Queer Theory] oferece uma maneira de desafiar outras ontologias" (Lee et al., 2008, p. 151). A principal uso da teoria queer em queering as categorias de gênero e sexualidade demonstra a possibilidade e a capacidade dela de confrontar outras categorias de identidades, tais como gerente, trabalhador e empreendedor (Lee et al., 2008; Phillips \& Knowles, 2012). Conceitos de performatividade e performance são úteis para se entender todas as formas de construção identitária e abrem um caminho interessante para se explorar identidades e identificação não apenas relacionadas a gênero e sexualidade, mas, inclusive, a identidades ocupacionais e corporativas (Phillips \& Knowles, 2012).

Por fim, apesar de se ter demonstrado que os conceitos queer aqui apresentados têm a capacidade de serem utilizados para além do estudo de minorias, gênero e sexualidade, principalmente na análise de identidades hegemônicas e identidades ocupacionais/corporativas, isto não significa que eles se restringem somente a essas aplicações nos estudos organizacionais. O futuro da teoria queer nos estudos organizacionais não pode ser de antemão previsto devido à historicidade, à fluidez e à dinâmica dos conceitos apresentados.

\section{Referências}

Adams, K. F. (2012). The discursive construction of professionalism: an episteme of the 21st century. Ephemera: Theory and Politics in Organization, 12(3), 327-343.

Alós, A. P. (2010). Narrativas da sexualidade: pressupostos para uma poética queer. Estudos Feministas, 18(3), 837-864. http://dx.doi.org/10.1590/S0104-026X2010000300011 
Andrade, L. F. S., Macedo, A. S., \& Oliveira, M. L. S. (2014). A produção científica em gênero no Brasil: um panorama dos grupos de pesquisa de administração [Edição Especial]. Revista de Administração Mackenzie, $\quad$ 15(6), 48-75. http://dx.doi.org/10.1590/167869712014/administracao.v15n6p48-75

Anzaldúa, G. (1991). To(o) queer the writer: loca, escrita y chicana. In B. Warland (Ed.), Versions: writing by dykes, queers and lesbians (pp. 249-263). Vancouver: Press Gang.

Baines, D. (2010a). Gender mainstreaming in a development project: intersectionality in a post-colonial un-doing? Gender, Work and Organization, 17(2), 119-149. http://dx.doi.org/10.1111/j.14680432.2009.00454.x

Baines, D. (2010b). In a different way: social unionism in the nonprofit social services - An Australian/Canadian comparison. Labor Studies Journal, 35(4), 480-502. http://dx.doi.org/10.1177/0160449X10365543

Barnard, I. (1999). Queer race. Social Semiotics, 9(2), 199-212. http://dx.doi.org/10.1080/10350339909360432

Beckett, C. (2012). Silence in the sexual agenda of a UK probation service. Equality, Diversity and $\begin{array}{llll}\text { Inclusion: } \quad \text { An } & \text { International }\end{array}$ http://dx.doi.org/10.1108/02610151211277617

Billing, Y. D. (2011). Are women in management victims of the phantom of the male norm? Gender, Work and Organization, 18(3), 298-317. http://dx.doi.org/10.1111/j.1468-0432.2010.00546.x

Borges, L. S. (2014). Feminismos, teoria queer e psicologia social crítica: (re)contando histórias. Psicologia \& Sociedade, 26(2), 280-289. http://dx.doi.org/10.1590/S0102-71822014000200005

Brewis, J., Hampton, M. P., \& Linstead, S. (1997). Unpacking Priscilla: subjectivity and identity in the organization of gendered appearance. Human Relations, 50(10), 1275-1304. http://dx.doi.org/10.1023/A:1016982423169

Brumer, A. (2009). Gênero, família e globalização. Sociologias, 11(21), 14-23. http://dx.doi.org/10.1590/S1517-45222009000100002

Bryant, A. (2003). Querying queer theory again (or queer theory as drag performance). Journal of Homosexuality, 45(24), 349-352. http://dx.doi.org/10.1300/J082v45n02_19

Butler, J. (1990). Gender trouble: feminism and the subversion of identity. New York: Routledge Classics.

Butler, J. (1993b). Bodies that matter: on the discursive limits of "sex". New York: Routledge.

Butler, J. (1993a). Critically queer. GLQ: A Journal of Lesbian and Gay Studies, 1(1), 17-32. http://dx.doi.org/10.1215/10642684-1-1-17

Butler, J. (2004). Undoing gender. Oxfordshire: Routledge.

Calás, M., Ou, H., \& Smircich, L. (2013). "Woman" on the move: mobile subjectivities after intersectionality. Equality, Diversity and Inclusion: An International Journal, 32(8), 708-731. http://dx.doi.org/10.1108/EDI-05-2012-0037

Cerqueira, P. R., \& Souza, E. M. (2015). Laclau, sexualidades e os corpos: análise das subjetivações ursinas. Psicologia \& Sociedade, 27(2), 267-279. http://dx.doi.org/10.1590/180703102015v27n2p267 
César, M. R. A. (2009). Gênero, sexualidade e educação: notas para uma "Epistemologia". Educar em Revista, (35), 37-51. http://dx.doi.org/10.1590/S0104-40602009000300004

Chidiac, M. T. V., \& Oltramari, L. C. (2004). Ser e estar drag queen: um estudo sobre a configuração da identidade queer. Estudos de Psicologia, 9(3), 471-478. http://dx.doi.org/10.1590/S1413294X2004000300009

Cohen, C. J. (1997). Punks, bulldaggers, and welfare queens: the radical potential of queer politics? GLQ: A Journal of Lesbian and Gay Studies, 3(4), 437-465. http://dx.doi.org/10.1215/106426843-4-437

Costa, C. L., \& Ávila, E. (2005). Gloria Anzaldúa, a consciência mestiça e o "feminismo da diferença". Estudos Feministas, 13(3), 691-703. http://dx.doi.org/10.1590/S0104-026X2005000300014

Du Gay, P. (2007). Organizing identity: persons and organizations after theory. London: SAGE Publications.

Duque, T. (2012). Reflexões teóricas, políticas e metodológicas sobre um morrer, virar e nascer travesti na adolescência. Estudos Feministas, 20(2), 489-500. http://dx.doi.org/10.1590/S0104026X2012000200010

Edwards, T. (2005). Queering the pitch? Gay masculinities. In M. S. Kimmel, J. Hearn, \& R. W. Connell (Eds.), Handbook of studies on men and masculinities (pp. 51-68). Thousand Oaks, London, Panchshell Enclave: Sage Publications.

Fernandes, E. R. (2015). Ativismo homossexual indígena: uma análise comparativa entre Brasil e América do Norte. DADOS Revista de Ciências Sociais, 58(1), 257-294. http://dx.doi.org/10.1590/00115258201544

Franco, N., \& Cicillini, G. A. (2015). Professoras trans brasileiras em seu processo de escolarização. Estudos Feministas, 23(2), 325-346. http://dx.doi.org/10.1590/0104-026X2015v23n2p325

Gamson, J. (2003). Sexualities, queer theory, and qualitative research. In N. Denzin \& Y. S. Lincoln (Eds.), The landscape of qualitative research: theories and issues (pp. 540-568). Thousand Oaks, California: Sage Publications.

Gardiner, J. K. (2005). Men, masculinities and feminist theory. In M. S. Kimmel, J. Hearn, \& R. w. Connell (Eds.), Handbook of studies on men \& masculinities (pp. 35-50). California: Sage Publications.

Gates, T. G. (2012). Why employment discrimination matters: well-being and the queer employee. Journal Workplace Rights, 16(1), 107-128. http://dx.doi.org/10.2190/WR.16.1.g

Gurrieri, L., \& Cherrier, H. (2013). Queering beauty: fatshionistas in the fatosphere. Qualitative Market Research: An International Journal, 16(3), 276-295. http://dx.doi.org/10.1108/13522751311326107

Halberstam, J. (2005). In a queer time and place: transgender bodies, subcultural lives. New York: New York University Press.

Halberstam, J. (2011). The queer art of failure. Durham and London: Duke University Press.

Halperin, D. M. (1995). Saint Foucault: towards a gay hagiography. Oxford: Oxford University Press.

Halperin, D. M. (2003). The normalization of queer theory. Journal of Homosexuality, 45(24), 339-343. http://dx.doi.org/10.1300/J082v45n02_17 
Harding, N., Lee, H., Ford, J., \& Learmonth, M. (2011). Leadership and charisma: a desire that cannot speak its name? Human Relations, 64(7), 927-949. http://dx.doi.org/10.1177/0018726710393367

Hill, R. J. (2009). Incorporating queers: blowback, backlash, and other forms of resistance to workplace diversity initiatives that support sexual minorities. Advances in Developing Human Resources, 11(1), 37-53. http://dx.doi.org/10.1177/1523422308328128

Jagose, A. R. (1996). Queer theory: an introduction. New York: New York University Press.

Johnson, E. P. (2008). Queer theory. In T. C. Davis (Ed.), The Cambridge companion to performance studies (pp. 166-181). Cambridge: Cambridge University Press.

Kenny, K. (2012). 'Someone big and important': identification and affect in an international development

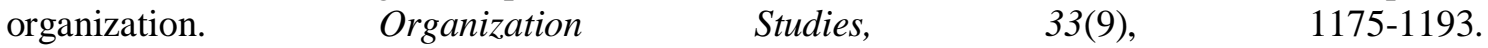
http://dx.doi.org/10.1177/0170840612448156

Kenny, K., \& Euchler, G. (2012). 'Some good clean fun': humour, control and subversion in an advertising agency. Gender, Work and Organization, 19(3), 306-323. http://dx.doi.org/10.1111/j.1468-0432.2012.00594.x

Kesetovic, Z. (2009). Understanding diversity in policing: Serbian perspectives. Policing: An International Journal of Police Strategies \& Management, 32(3), 431-445. http://dx.doi.org/10.1108/13639510910981590

King, A. (2016). Queer categories: queer(y)ing the identification 'older lesbian, gay and/or bisexual (LGB) adults' and its implications for organizational research, policy and practice. Gender, Work and Organization, 23(1), 7-18. http://dx.doi.org/10.1111/gwao.12065

Lauretis, T. (1991). Queer theory: lesbian and gay sexualities. Differences: a Journal of Feminist Cultural Studies, 3(2), iii-xviii.

Lee, H., Learmonth, M., \& Harding, N. (2008). Quee(y)ing public administration. Public Administration, 86(1), 149-167. http://dx.doi.org/10.1111/j.1467-9299.2007.00707.x

Linstead, A., \& Brewis, J. (2004). Beyond boundaries: towards fluidity in theorizing and practice. Gender, Work and Organization, 11(4), 355-362. http://dx.doi.org/10.1111/j.14680432.2004.00237.x

Litvin, S. W. (2008). Sensation seeking and its measurement for tourism research. Journal of Travel Research, 46(4), 440-445. http://dx.doi.org/10.1177/0047287507308326

Lovaas, K. E., \& Jenkins, M. M. (2007). Introduction: setting the stage. In K. E. Lovaas \& M. M. Jenkins (Eds.), Sexualities and communication in everyday life: a reader (pp. 1-18). California: Sage Publications.

McDonald, J. (2013). Coming out in the field: a queer reflexive account of shifting researcher identity. Management Learning, 44(2), 127-143. http://dx.doi.org/10.1177/1350507612473711

Miskolci, R. (2007, julho). A teoria queer e a questão das diferenças: por uma analítica da normalização (queer theory and sociology: the challenging analysis of normalization). Anais do Congresso de Leitura do Brasil, Campinas, SP, Brasil,16.

Miskolci, R. (2009b). A teoria queer e a sociologia: o desafio de uma analítica da normalização (queer theory and sociology: the challenge of analysis of normalization). Sociologias, 11(21), 150-182. http://dx.doi.org/10.1590/S1517-45222009000100008 
Miskolci, R. (2009a). O vértice do triângulo: Dom Casmurro e as relações de gênero e sexualidade no fin-desiècle brasileiro. Estudos Feministas, 17(2), 547-567. http://dx.doi.org/10.1590/S0104026X2009000200014

Miskolci, R., \& Balieiro, F. F. (2011). O drama público de Raul Pompeia: sexualidade e política no Brasil finissecular. Revista Brasileira de Ciências Sociais, 26(75), 73-88. http://dx.doi.org/10.1590/S0102-69092011000100004

Motta, J. I. J., \& Ribeiro, V. M. B. (2013). Quem educa queer: a perspectiva de uma analítica queer aos processos de educação em saúde. Ciência \& Saúde Coletiva, 18(6), 1695-1704. http://dx.doi.org/10.1590/S1413-81232013000600021

Muhr, S. L., \& Sullivan, K. R. (2013). "None so queer as folk": gendered expectations and transgressive bodies in leadership. Leadership, 9(3), 416-435. http://dx.doi.org/10.1177/1742715013485857

Parker, M. (2001). Fucking management: queer, theory and reflexivity. Ephemera: Critical Dialogues on Organization, 1(1), 36-53.

Philbrook, C. G. (2003). Queer theory and performance. Journal of Homosexuality, 45(24), 353-356. http://dx.doi.org/10.1300/J082v45n02_20

Phillips, M., \& Knowles, D. (2012). Performance and performativity: undoing fictions of women business owners. Gender, Work and Organization, 19(4), 416-437. http://dx.doi.org/10.1111/j.1468-0432.2010.00528.x437

Pino, N. P. (2007). Queer theory and the intersex: invisible experiences of un-done bodies. Cadernos Pagu, (28), 149-174. http://dx.doi.org/10.1590/S0104-83332007000100008

Pullen, A., \& Linstead, S. (2005). Introduction: organizing identity, interrupting identity. In A. Pullen \& S. Linstead (Eds.), Organization and identity (pp. 1-19). London: Routledge.

Quinn, V., \& Sinfield, A. (2006). Queer theory. Year's Work in Critical and Cultural Theory, 14(1), 143-151. http://dx.doi.org/10.1093/ywcct/mbl008

Richardson, B. K., \& McGlynn, J. (2011). Rabid fans, death threats, and dysfunctional stakeholders: the influence of organizational and industry contexts on whistle-blowing cases. Management Communication Quarterly, 25(1), 121-150. http://dx.doi.org/10.1177/0893318910380344

Rodrigues, C. (2012). Performance, gênero, linguagem e alteridade: J. Butler leitora de J. Derrida. Revista Latinoamericana Sexualidad, Salud y Sociedad, (10), 140-164. http://dx.doi.org/10.1590/S1984-64872012000400007

Rosenbaum, M., Walsh, G., \& Wozniak, R. (2012). Family allowances as reverse retail discrimination. International Journal of Retail \& Distribution Management, 40(5), 342-359. http://dx.doi.org/10.1108/09590551211222321

Rumens, N. (2008a). The complexities of friendship: exploring how gay men make sense of their workplace friendship with straight women. Culture and Organizations, 14(1), 79-95. http://dx.doi.org/10.1080/14759550701864918

Rumens, N. (2008b). Working at intimacy: gay men's workplace friendships. Gender, Work and Organization, 15(1), 9-30. http://dx.doi.org/10.1111/j.1468-0432.2007.00364.x

Rumens, N. (2010). Workplace friendships between men: gay men's perspectives and experiences. Human Relations, 63(10), 1541-1562. http://dx.doi.org/10.1177/0018726710361987 
Rumens, N. (2012). Queering cross-sex friendships: an analysis of gay and bisexual men's workplace friendships with heterosexual women. Human Relations, 65(8), 955-978. http://dx.doi.org/10.1177/0018726712442427

Sampaio, J. V., \& Germano, I. M. P. (2014). Políticas públicas e crítica queer algumas questões sobre identidade. Psicologia \& Sociedade, 26(2), 290-300. http://dx.doi.org/10.1590/S010271822014000200006

Schmidt, S. W., Githens, R. P., Rocco, T. S., \& Kormanik, B. M. (2012). Lesbians, gays, bisexuals, and transgendered people and human resource development: an examination of the literature in adult education and human resource development. Human Resource Development Review, 11(3), 326348. http://dx.doi.org/10.1177/1534484312447193

Scurry, T., Rodriguez, J. K., \& Bailouni, S. (2013). Narratives of identity of self-initiated expatriates in Qatar. $\quad$ Career Development International, 18(1), 12-33. http://dx.doi.org/10.1108/13620431311305926

Sedgwick, E. K. (2008). Epistemology of the closet. Berkeley, Los Angeles, London: University of California Press.

Seidman, S. (1996). Queer theory/sociology. Cambridge/Oxford: Blackwell Publishers.

Seidman, S. (2006). Theoretical perspectives. In S. Seidman, N. Fischer, \& C. Meeks (Eds.), Handbook of the new sexuality studies (pp. 3-13). New York: Routledge.

Souza, E. M., \& Carrieri, A. P. (2010). A analítica queer e seu rompimento com a concepção binária de gênero. Revista de Administração Mackenzie, 11(3), 46-70. http://dx.doi.org/10.1590/S167869712010000300005

Souza, E. M. de, \& Carrieri, A. de P. (2015). When invisibility is impossible body, subjectivity, and labor among travestis and transsexuals. Journal of Workplace Rights (Sage Open), 5, 1-11. http://dx.doi.org/10.1177/2158244015585406

Souza, E. M., \& Pereira, S. J. N. (2013). (Re)produção do heterossexismo e da heteronormatividade nas relações de trabalho: a discriminação de homossexuais por homossexuais. Revista de Administração Mackenzie, 14(4), 76-105. http://dx.doi.org/10.1590/S1678-69712013000400004

Souza, E. M., Bianco, M. F., \& Junquilho, G. S. (2015). Contestações sobre o masculino no contexto do trabalho: estudo pós-modernista em mineradoras e siderurgias [ $3^{\text {a }}$ Edição Especial]. Revista de Administração Contemporânea, 19, 269-287. Recuperado de http://www.scielo.br/pdf/rac/v19nspe3/1415-6555-rac-19-spe3-00269.pdf. http://dx.doi.org/10.1590/1982-7849rac20151545

Souza, E. M., Corvino, M. M. F., \& Lopes, B. C. (2013). Uma análise dos estudos sobre o feminino e as mulheres na área de administração: a produção científica brasileira entre 2000 a 2010. Organizações \& Sociedade, 20(67), 603-621. http://dx.doi.org/10.1590/S198492302013000400003

Steyaert, C. (2015). Three women. A kiss. A Life. On the queer writing of time in organization. Gender, Work and Organization, 22(2), 163-178. http://dx.doi.org/10.1111/gwao.12075

Sullivan, N. (2003). A critical introduction to queer theory. New York: New York University Press.

Taylor, T., Mallinson, C., \& Bloch, K. (2008). "Looking for a few good women": volunteerism as an interaction in two organizations. Nonprofit and Voluntary Sector Quarterly, 37(3), 389-410. http://dx.doi.org/10.1177/0899764007310420 
Thanem, T. (2010). Free at last? Assembling, producing and organizing sexual spaces in Swedish sex education. Gender, Work and Organization, 17(1), 91-112. http://dx.doi.org/10.1111/j.14680432.2009.00440.x

Turner, W. B. (2000). A genealogy of queer theory. Philadelphia: Temple University Press.

Tyler, M., \& Cohen L. (2008). Management in/as comic relief: queer theory and gender performativity in the office. Gender, Work and Organization, 15(2), 113-132. http://dx.doi.org/10.1111/j.14680432.2007.00351.x

Tyler, M., \& Cohen, L. (2010). Spaces that matter: gender performativity and organizational space. Organization Studies, 31(2), 175-198. http://dx.doi.org/10.1177/0170840609357381

Warner, M. (1993). Introduction. In M. Warner (Ed.), Fear of a queer planet: queer politics and social theory (pp. vii-xxxi). Minneapolis: University of Minnesota Press.

Warner, M. (2012). Queer and then? The end of queer theory? The Chronicle of Higher Education, $58(18), 1-5$.

Watson, K. (2005). Queer theory. Group Analysis, 38(1), 67-81. http://dx.doi.org/10.1177/0533316405049369

Weeks, J. (1995). Invented moralities: sexual values in an age of uncertainty. New York: Columbia University Press.

Willis, P. (2012). Witnesses on the periphery: young lesbian, gay, bisexual and queer employees witnessing homophobic exchanges in Australian workplaces. Human Relations, 65(12), 15891610. http://dx.doi.org/10.1177/0018726712457795

\section{Dados do Autor}

Eloisio Moulin de Souza

Av. Fernando Ferrari, 514, Goiabeiras, 29075-910, Vitória, ES, Brasil. E-mail: eloisiomoulin@ gmail.com 